\title{
Effect of Oxide Nanoparticles on Thermal and Mechanical Properties of Electrospun Separators for Lithium-Ion Batteries
}

\author{
Marco Zaccaria, ${ }^{1}$ Chiara Gualandi, ${ }^{2}$ Davide Fabiani, ${ }^{1}$ \\ Maria Letizia Focarete, ${ }^{2}$ and Fausto Croce $^{3}$ \\ ${ }^{1}$ Electrical Engineering Department, Alma Mater Studiorum-University of Bologna, Viale Risorgimento 2, 40136 Bologna, Italy \\ ${ }^{2}$ Chemistry Department and National Consortium of Materials Science and Technology (INSTM, RU Bologna), \\ Alma Mater Studiorum-University of Bologna, Via Selmi 2, 40126 Bologna, Italy \\ ${ }^{3}$ Dipartimento di Scienze del Farmaco, Universitá “G. d’Annunzio", Via dei Vestini 31, 66100 Chieti, Italy \\ Correspondence should be addressed to Marco Zaccaria, marco.zaccaria@unibo.it
}

Received 23 July 2012; Revised 20 September 2012; Accepted 1 October 2012

Academic Editor: Russell E. Gorga

Copyright ( $) 2012$ Marco Zaccaria et al. This is an open access article distributed under the Creative Commons Attribution License, which permits unrestricted use, distribution, and reproduction in any medium, provided the original work is properly cited.

This study reports the fabrication and characterization of poly(ethylene oxide) (PEO) and poly(vinylidenefluoride-cochlorotrifluoroethylene) (PVDF-CTFE) nanofibrous separators for lithium-ion batteries loaded with different amounts of fumedsilica and tin oxide nanoparticles. Membrane morphological characterization (SEM, TEM) showed the presence of good-quality nanofibres containing nanoparticles. Thermal degradation and membrane mechanical properties were also investigated, and a remarkable effect of nanoparticle addition on membrane mechanical properties was found. In particular, PEO membranes were strengthened by the addition of metal oxide, whereas PVDF-CTFE membranes acquired ductility.

\section{Introduction}

Metallic lithium and lithium-ion batteries might play a key role both in the field of electric vehicles and in stationary applications such as energy storage, in particular if coupled with renewable energy plants. Currently, these batteries are rarely used in high-power applications because they still present relatively low values of specific energy, high costs, and safety problems.

A lithium-ion battery is generally composed by (1) graphite anode, (2) lithium-metal oxide cathode, (3) electrolyte solution containing lithium salts, and (4) polymeric separator. The latter is often a key component of the battery [1-3]. In fact, the separator should be electrically insulating for electronic charges and, at the same time, it should be enough porous to ensure electrolyte uptake to allow ionic conductivity. Large ionic conductivity is an essential prerequisite for the battery functioning. Moreover, good mechanical properties, as well as high dimensional stability at high temperature of the polymeric separator, are necessary to prevent the short-circuit between anode and cathode, which can eventually lead to battery explosion. In the literature several materials have been investigated as polymeric separators and gel-forming polymers, for example, polyethylene (PE), polypropylene (PP), polyethylene oxide (PEO), polyvinylidene fluoride (PVDF), and copolymers of the latter. Most of the batteries nowadays in the market make use of PVDF separators obtained by means of phase inversion method (especially through solvent casting) $[4,5]$. Nanoparticles of metal oxide added to the polymeric material can provide a substantial contribution in terms of electrical conductivity, as well as a greater thermal stability of the inner components of the battery and greater mechanical strength, thus contributing to improve cell safety [6-11]. Nanosilica is one of the most investigated filler due to its properties, such as ability to improve the transfer of lithium ions and absorption of the electrolyte, thus increasing ion conductivity, stability at the electrode interface and mechanical strength $[12,13]$.

Very recently electrospinning technology [14] was used to produce separators with high porosities in form of nonwoven membranes possessing high surface area and 
characterized by a large electrolyte uptake, therefore capable of ensuring enhanced ionic conductivity also thanks to pore interconnectivity [15-17]. Further improvements in electrical and mechanical properties have been achieved by incorporating nanoparticles of metal oxides in electrospun polymeric fibres $[4,18,19]$. This study reports on the fabrication and characterization of poly(ethylene oxide) (PEO) and poly(vinylidenefluoride-co-chlorotrifluoroethylene) (PVDF-CTFE) nanofibrous separators realized through the electrospinning technique. Nanofillers of fumed silica and tin oxide were added to polymeric solutions at different concentrations, and morphological, thermal, and mechanical characterization of the membranes was carried out.

\section{Experimental}

2.1. Materials. Poly(ethylene oxide) (PEO $M_{v}=1 \times$ $10^{6} \mathrm{~g} / \mathrm{mol}$ ) was purchased from Sigma-Aldrich and poly(vinylidenefluoride-co-chlorotrifluoroethylene) (PVDF-CTFE, $10 \mathrm{~mol} \%$ CTFE, $8 \mathrm{cl} \mathrm{g}^{-1}$ intrinsic viscosity) was kindly provided by Solvay Solexis. Fumed silica nanoparticles (average size $=7 \mathrm{~nm}$ ) and tin oxide nanoparticles (size $<100 \mathrm{~nm}$ ) were purchased form Sigma-Aldrich. Acetone (Ac) and Dimethylacetamide (DMAc) were purchased from SigmaAldrich and were used without further purification.

2.2. Membrane Separators Fabrication. The electrospinning apparatus, made in house, was composed of a high voltage power supply (Spellman, SL 50 P 10/CE/230), a syringe pump (KDScientific 200 series), a glass syringe, a stainlesssteel blunt-ended needle (inner diameter: $0.84 \mathrm{~mm}$ ) connected with the power supply electrode and a grounded aluminum plate-type collector $\left(7 \times 7 \mathrm{~cm}^{2}\right)$. The polymer solution was dispensed through a Teflon tube to the needle that was vertically placed on the collecting plate. PEO was dissolved at a concentration of $4 \% \mathrm{w} / \mathrm{v}$ in bidistillated water. PVDF-CTFE was dissolved at a concentration of $15 \% \mathrm{w} / \mathrm{v}$ in Ac:DMAc $(70: 30, \mathrm{v} / \mathrm{v})$. After polymer dissolution, nanoparticles were added to polymeric solutions in proper amounts in order to produce a final membrane containing either $5 \% \mathrm{w} / \mathrm{w}$ or $10 \% \mathrm{w} / \mathrm{w}$ of either fumed-silica or tin oxide. PEO solutions were electrospun by using the following conditions: voltage $=15 \mathrm{kV}$, needle-to-collector distance $=$ $20 \mathrm{~cm}$, flow rate $=0.005 \mathrm{~mL} / \mathrm{min}$. PVDF-CTFE solutions were electrospun by using the following conditions: voltage $=17 \mathrm{kV}$, needle-to-collector distance $=15 \mathrm{~cm}$, flow rate $=$ $0.01 \mathrm{~mL} / \mathrm{min}$. A quality control was performed in order to verify homogeneity of sample thickness by means of a digital micrometer. Only specimens having thicknesses in the range of $50 \pm 10 \mu \mathrm{m}$ were used for further measurements.

2.3. Methods. Scanning Electron Microscope (SEM) observations were carried out using a Philips 515 SEM equipped with energy dispersed X-ray spectrometer (EDS) by applying an accelerating voltage of $15 \mathrm{kV}$ on samples sputtercoated with gold. The distribution of fibre diameters was determined through the measurement of about 200 fibres by
TABLE 1: Fibre diameter distribution of electrospun membranes.

\begin{tabular}{lcc}
\hline Polymer & Nanoadditive & $\begin{array}{c}\text { Average diameter } \pm \\
\text { standard deviation } \\
(\mathrm{nm})\end{array}$ \\
\hline \multirow{2}{*}{$\mathrm{PEO}$} & - & $370 \pm 50$ \\
& $5 \mathrm{wt} \% \mathrm{SiO}_{2}$ & $380 \pm 70$ \\
& $10 \mathrm{wt} \% \mathrm{SiO}_{2}$ & $420 \pm 80^{\mathrm{a}}$ \\
& $5 \mathrm{wt} \% \mathrm{SnO}_{2}$ & $370 \pm 60$ \\
PVDF-CTFE & $10 \mathrm{wt} \% \mathrm{SnO}_{2}$ & $400 \pm 50^{\mathrm{a}}$ \\
& $-\mathrm{wt}_{\mathrm{SiO}}$ & $280 \pm 70$ \\
& $10 \mathrm{wt} \% \mathrm{SiO}_{2}$ & $310 \pm 90^{\mathrm{b}}$ \\
& $5 \mathrm{wt} \% \mathrm{SnO}_{2}$ & $370 \pm 150^{\mathrm{b}}$ \\
\end{tabular}

versus PEO $P<0.05$

bersus PVDF-CTFE $P<0.05$.

means of an acquisition and image analysis software (EDAX Genesis), and the results were given as the average diameter \pm standard deviation. The one-way ANOVA test was performed in order to check the statistical significance of the difference between the mean values $(P<0.05)$. Thermogravimetric analysis (TGA) measurements were performed with a TA Instruments TGA2950 thermogravimetric analyzer from RT to $700^{\circ} \mathrm{C}$ (heating rate $10^{\circ} \mathrm{C} \mathrm{min}^{-1}$, purge gas air). Electrospun fibres supported on conventional copper microgrids were observed by using a Philips CM 100 transmission electron microscope (TEM) operating at $80 \mathrm{kV}$. Stress-strain measurements were performed with an Instron 4465 tensile testing machine on rectangular electrospun membranes ( $5 \mathrm{~mm}$ wide) according to ASTM D882-02 standard. The gauge length was $20 \mathrm{~mm}$ and the cross-head speed was $2 \mathrm{~mm} \mathrm{~min}{ }^{-1}$. Load-displacement curves were obtained and converted to stress-strain curves. Test were carried out on seven specimens for each sample, and results were processed through the Weibull probability distribution of elastic modulus, stress at break and elongation at break, providing the 63.2th percentiles (alpha) and the mean values with the relevant confidence intervals at $95 \%$ probability.

\section{Results and Discussions}

Electrospun membranes of PEO and PVDF-CTFE containing different amounts of either fumed-silica or tin oxide were produced. The addition of both type of nanoparticles to $\mathrm{PEO}$ solutions provided homogeneous suspensions that were electrospun to fabricate $5 \% \mathrm{wt}$ and $10 \% \mathrm{wt}$ nanoparticleloaded fibres. In the case of PVDF-CTFE solutions, only $\mathrm{SiO}_{2}$ provided homogeneous suspensions when added at both low and high concentration. On the contrary, $\mathrm{SnO}_{2}$ nanoparticles precipitated when added at $10 \%$ wt to PVDF-CTFE solution, thus PVDF-CTFE fibres loaded with $\mathrm{SnO}_{2}$ were prepared by using only a low additive amount $(5 \% \mathrm{wt})$. Figures 1 and 2 show SEM images of electrospun membranes. All samples are made of bead-free fibres with average fibre diameter reported in Table 1. PEO membrane is composed of fibre with average diameter of $370 \pm 50 \mathrm{~nm}$. When nanoparticles are added at 


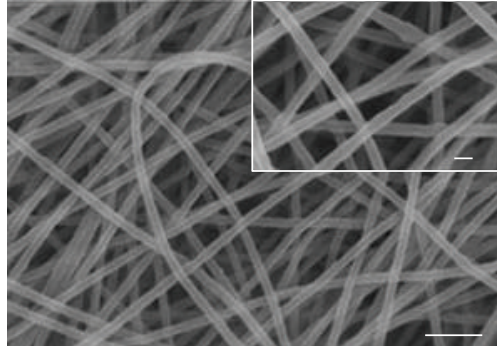

(a)

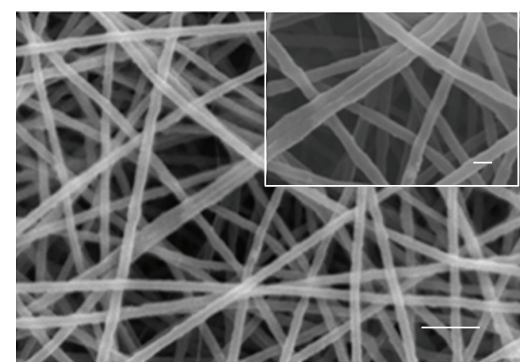

(b)

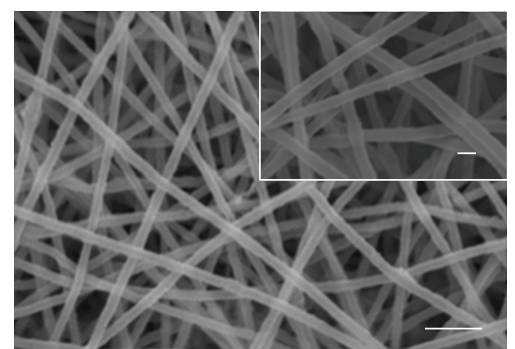

(c)

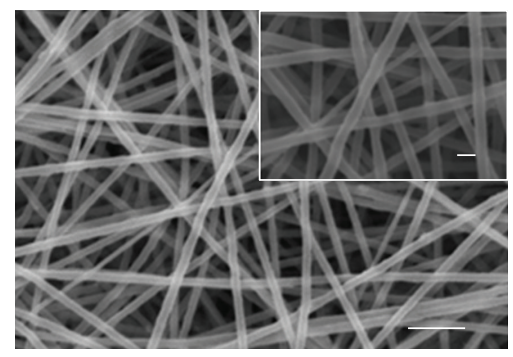

(d)

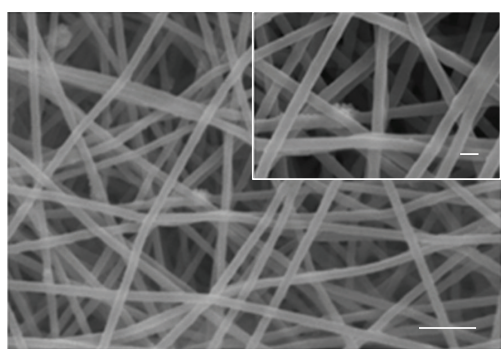

(e)

Figure 1: SEM images of PEO electrospun membranes (a) and PEO electrospun membranes containing $\mathrm{SiO}_{2} 5 \mathrm{wt} \%$ (b), $\mathrm{SiO}_{2} 10 \mathrm{wt} \%$ (c), $\mathrm{SnO}_{2} 5 \mathrm{wt} \%$ (d) and $\mathrm{SnO}_{2} 10 \mathrm{wt} \%$ (e). Scale bar $=2 \mu \mathrm{m}$; insert scale bar $=0.5 \mu \mathrm{m}$.

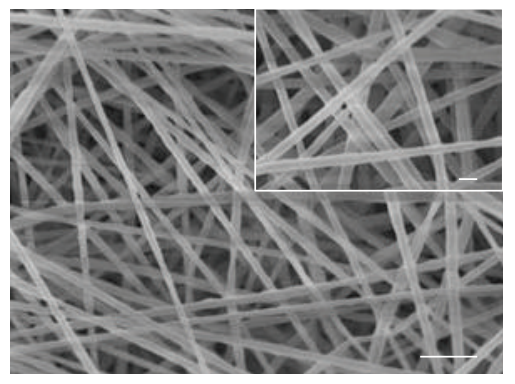

(a)

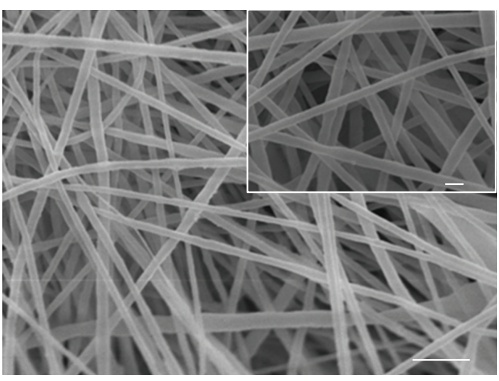

(b)

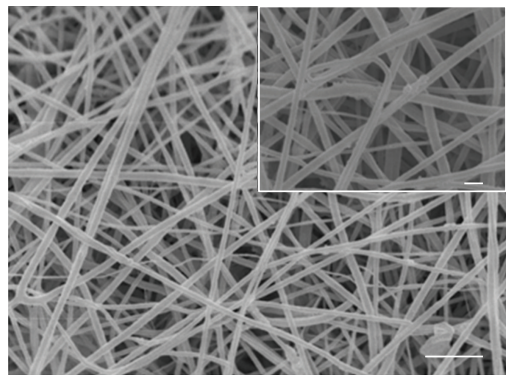

(d)

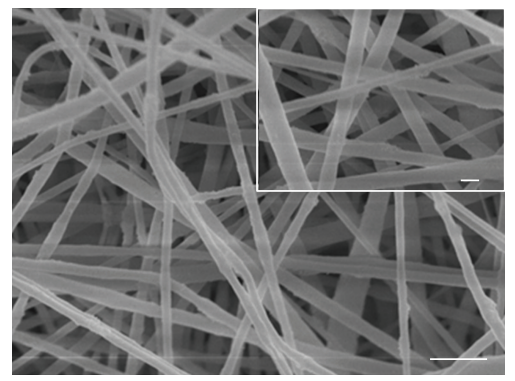

(c)

FIGURE 2: SEM images of PVDF-CTFE electrospun membranes (a) and PVDF-CTFE electrospun membranes containing $\mathrm{SiO}_{2} 5 \mathrm{wt} \%$ (b), $\mathrm{SiO}_{2} 10 \mathrm{wt} \%$ (c), and $\mathrm{SnO}_{2} 5 \mathrm{wt} \%$ (d). Scale bar $=2 \mu \mathrm{m}$; insert scale bar $=0.5 \mu \mathrm{m}$.

high concentration to PEO solution, the resulting fibres show higher diameter. PVDF-CTFE pristine fibres have average diameter of $280 \pm 70 \mathrm{~nm}$ that increase when loaded with silica nanoparticles. On the contrary, the addition of tin oxide to PVDF-CTFE solution results in thinner fibres. The change of fibre dimension with the addition of nanoparticles can be the consequence of changes of polymer solution properties such as surface tension, conductivity, and viscosity that are wellknown to be crucial in defining fibre morphology [14, $20]$.

The presence of nanoadditive within the nanofibres is investigated by means of EDS spectroscopy. Figures 3 and 4 report EDS spectra of PEO and PVDF-CTFE membranes, respectively. The spectra are reported in the range $0-8 \mathrm{keV}$ 


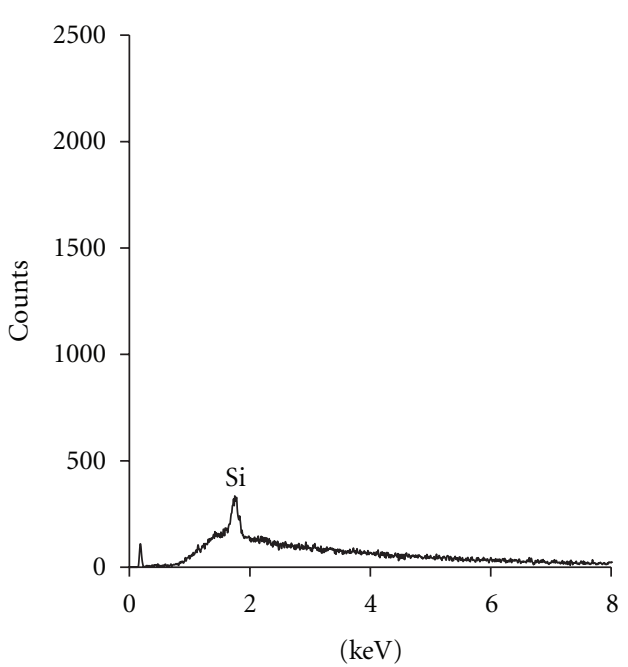

(a)

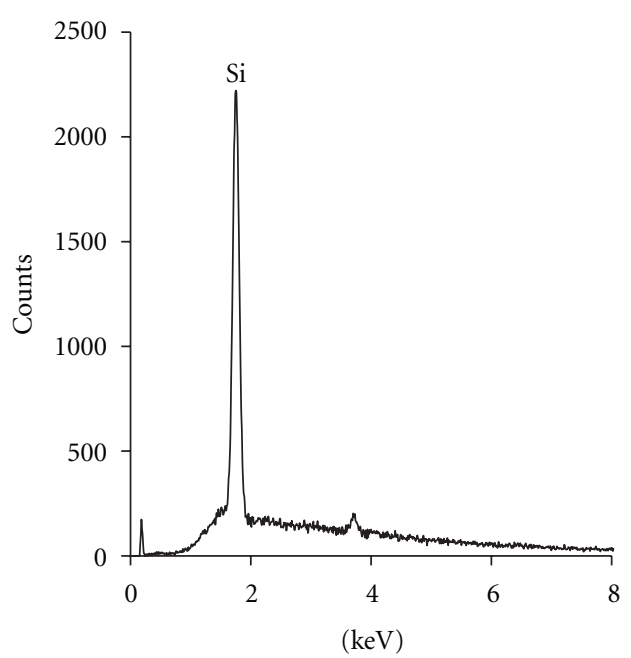

(c)

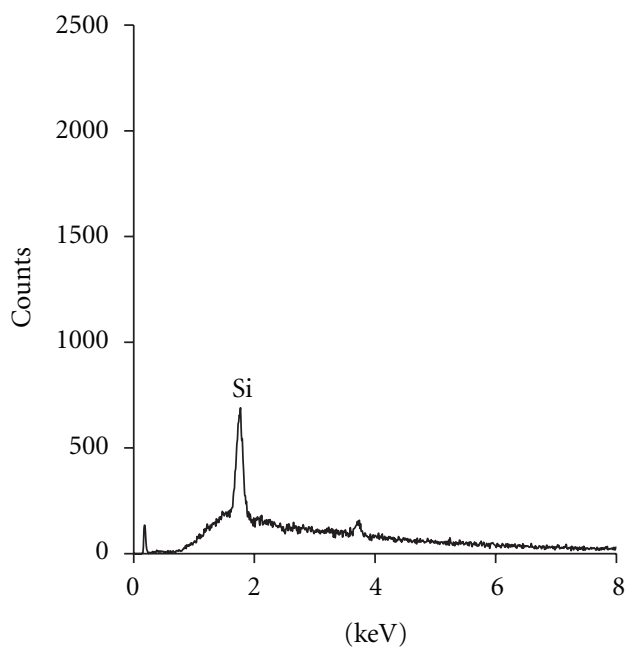

(b)

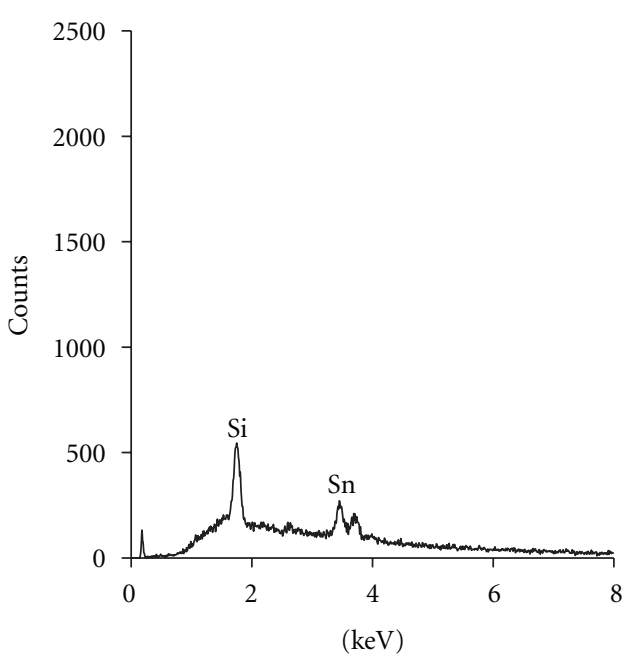

(d)

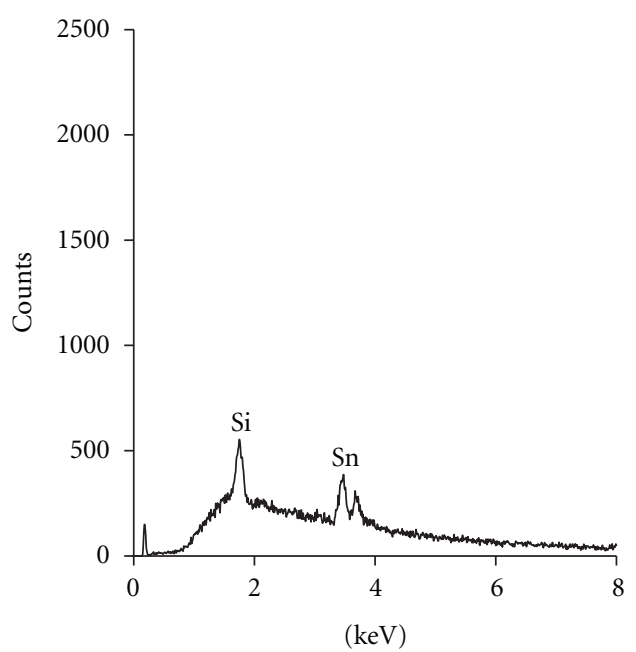

(e)

FIgURE 3: EDS spectra of PEO electrospun membranes (a) and PEO electrospun membranes containing $\mathrm{SiO}_{2} 5 \mathrm{wt} \%$ (b), $\mathrm{SiO}_{2} 10 \mathrm{wt} \%$ (c), $\mathrm{SnO}_{2} 5 \mathrm{wt} \%$ (d), and $\mathrm{SnO}_{2} 10 \mathrm{wt} \%$ (e). 


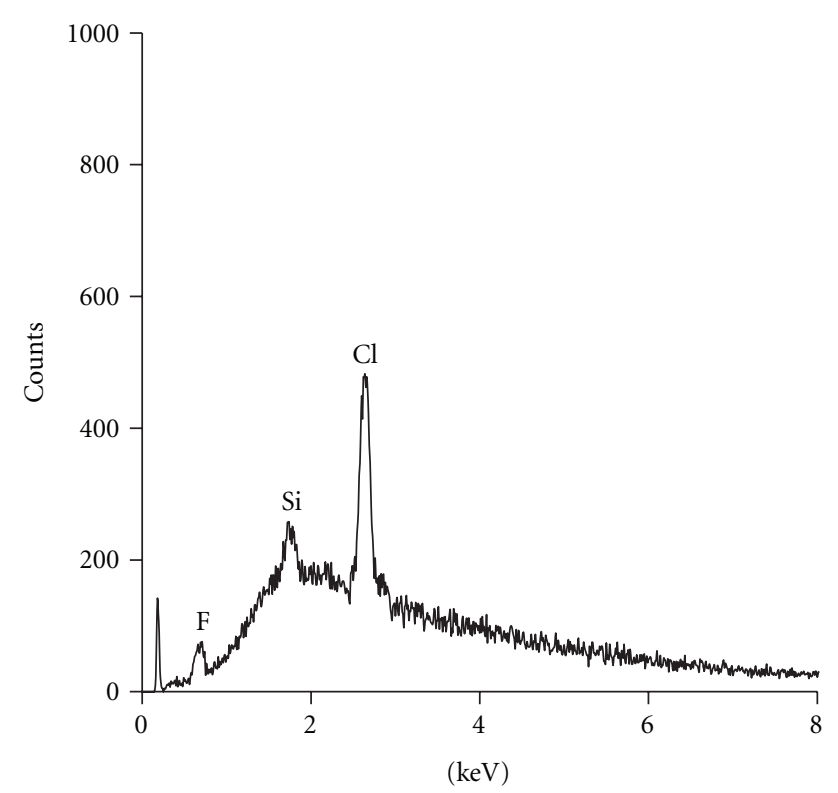

(a)

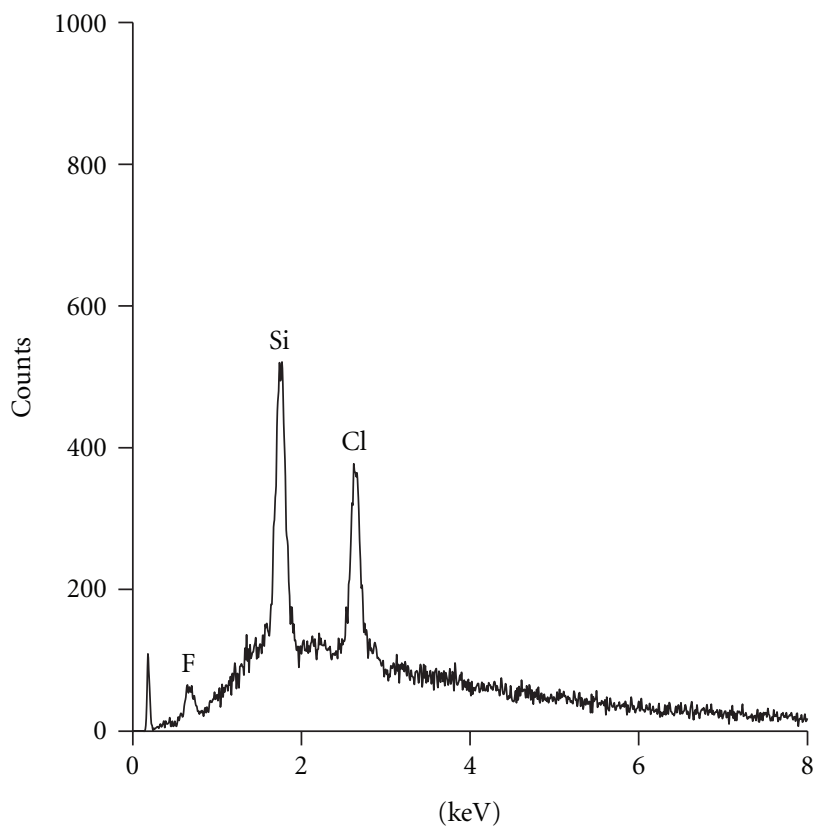

(c)

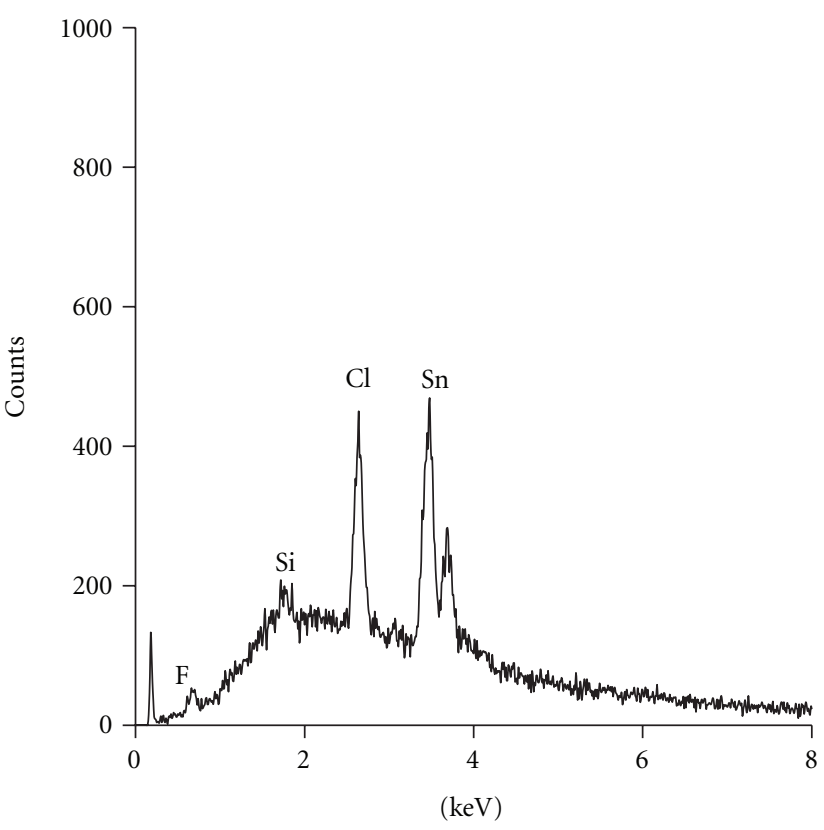

(b)

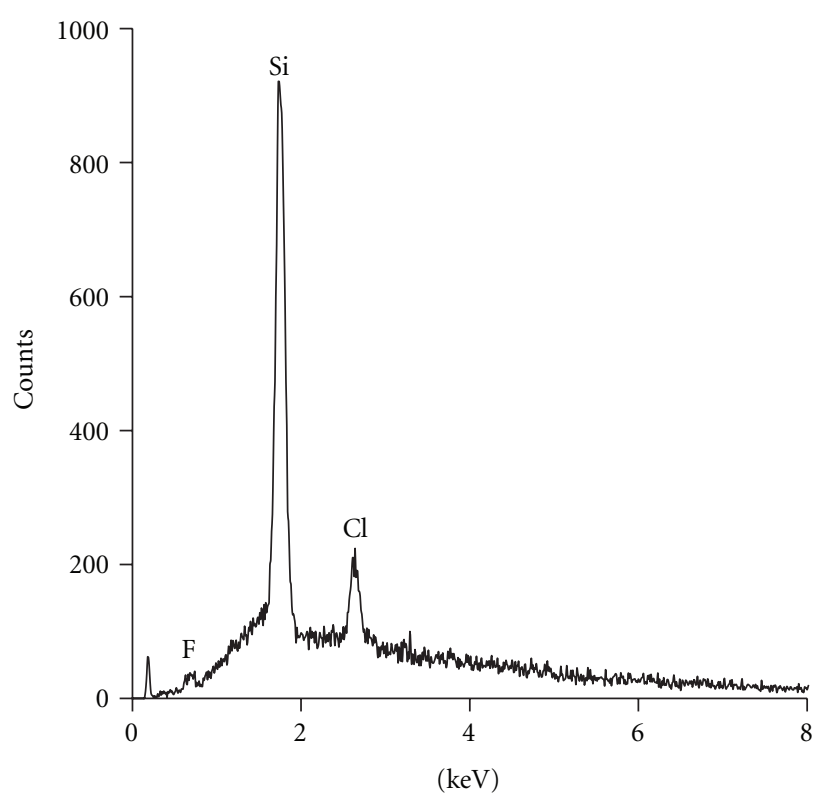

(d)

FIGURE 4: EDS spectra of PVDF-CTFE electrospun membranes (a) and PVDF-CTFE electrospun membranes containing SnO $25 \mathrm{wt} \%$ (b), $\mathrm{SiO}_{2} 5 \mathrm{wt} \%$ (c), and $\mathrm{SiO}_{2} 10 \mathrm{wt} \%$ (d).

since at energies higher than $8 \mathrm{keV}$ no peaks are detected. PEO membranes show peaks ascribable to either Si or Sn atoms according to the nature of the additive with intensity proportional to additive content. Pristine PVDF-CTFE displays peaks ascribable to $\mathrm{Cl}$ and $\mathrm{F}$, while the membranes loaded with nanoparticles show peaks of Si (Figures 4(c) and 4(d)) and Sn (Figure 4(b)).

Membrane thermal stability is evaluated through TGA measurements. Figure 5 shows TGA curves of PEO and
PVDF-CTFE samples performed in air atmosphere. PEO starts degrading at about $150^{\circ} \mathrm{C}$ and degradation occurs in a single step, with a temperature of maximum rate of weight loss at about $290^{\circ} \mathrm{C}$. PEO without additive has a $5 \%$ of residue at $700^{\circ} \mathrm{C}$. Samples loaded with nanoparticles have a higher residue than the sample of pure PEO, between 8 and $11 \%$. By considering the intrinsic residual weight of PEO (5\%) it is possible to calculate the actual nanoparticle content from TGA residual weight of electrospun-loaded 


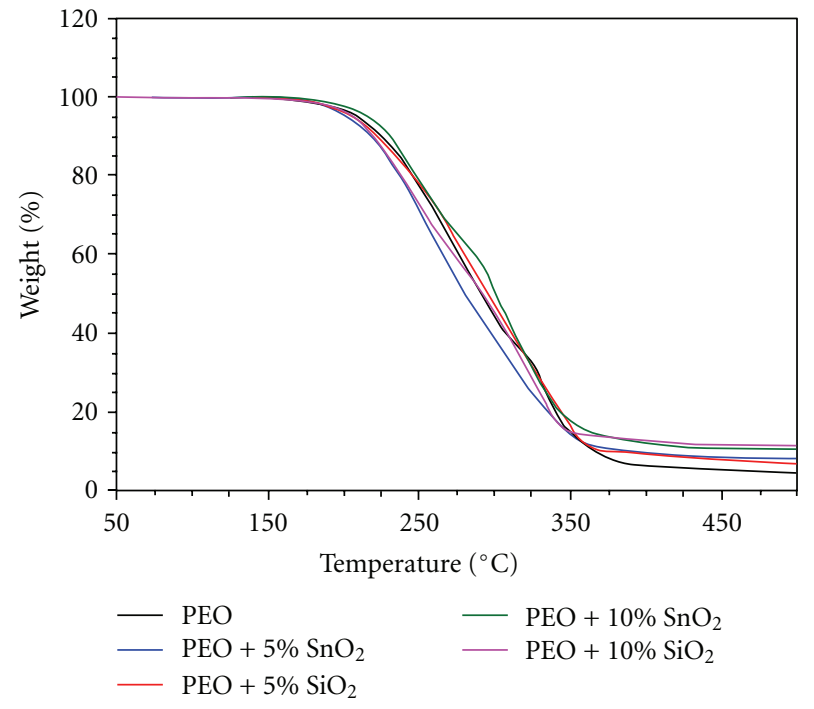

(a)

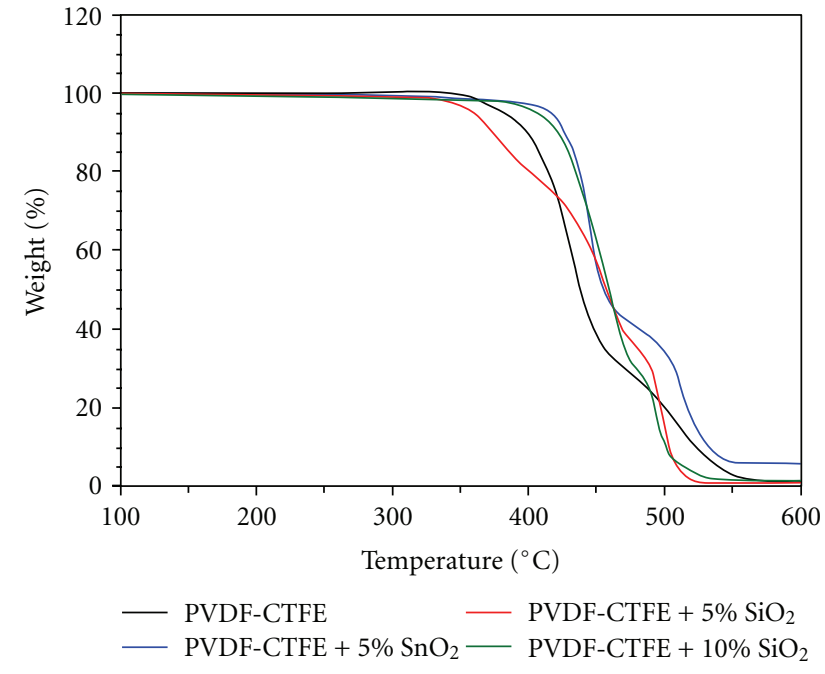

(b)

FIgURE 5: Thermogravimetric curves of PEO (a) and PVDF-CTFE (b) samples.

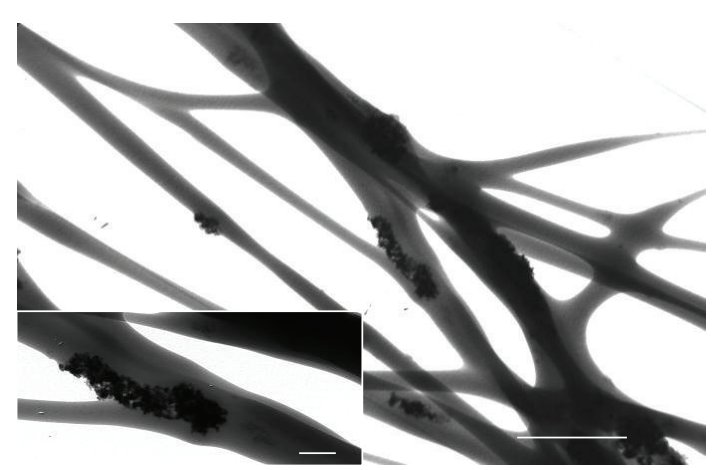

Figure 6: TEM images of electrospun PEO containing 10\% wt $\mathrm{SnO}_{2}$. Scale bar $=1 \mu \mathrm{m}$; insert scale bar $=200 \mathrm{~nm}$.

samples: the actual particles content is $4 \%, 6 \%, 3 \%$ and $7 \%$ for $\mathrm{PEO}+5 \% \mathrm{SnO}_{2}, \mathrm{PEO}+10 \% \mathrm{SnO}_{2}, \mathrm{PEO}+5 \% \mathrm{SiO}_{2}$, and $\mathrm{PEO}+10 \% \mathrm{SiO}_{2}$, respectively. PVDF-CTFE samples start to degrade around $350-400^{\circ} \mathrm{C}$. PVDF-CTFE without nanoparticles reaches zero mass at the end of the test, as expected. The sample containing tin oxide at 5\% has a residue equal to about $5 \%$ of the initial mass. The curves related to samples containing silica tend to zero. This should evidence the total absence in the material of silicon oxide. However, it can be hypothesized that during the degradation of the material, some compounds of silicon were generated. In particular it can be assumed that the presence of hydrogen, chlorine, and fluorine leads to the formation of silane $\left(\mathrm{SiH}_{4}\right)$, tetrafluorosilane $\left(\mathrm{SiF}_{4}\right)$, or tetrachlorosilane $\left(\mathrm{SiCl}_{4}\right)$. All these compounds are in gaseous form at temperatures of our interest and therefore justify the absence of residual mass.

Figure 6 shows TEM images of a representative sample of PEO membrane loaded with $10 \%$ wt of $\mathrm{SnO}_{2}$. Differently from fibres of pristine polymer, that are homogeneous, fibres containing nanoadditives show the presence of aggregated nanoparticles that, in some cases, protrude to the outer surface of the fibres. Optimization of polymer suspension preparation will enable to improve particle dispersion within the fibres. The particle shape is spherical and their size is between 10 and 40 nanometers. This result is in perfect agreement with the indications of the average particle size, given by the supplier.

In the design of a battery separator membrane, the evaluation of mechanical properties is an important issue to take into consideration. Membranes should present dimensional stability as well as sufficient mechanical strength to allow handling, while maintaining good ionic conductivity. Figure 7 shows elastic modulus, stress at break, and elongation at break of PEO and PVDF-CTFE membranes. Bar plots report also confidence intervals at 95\%, according to Weibull probability distribution. The increase of tensile strength shown by PEO samples with $5 \%$ of tin oxide and with $10 \%$ of fumed silica with respect to pristine $\mathrm{PEO}$ is significantly larger than the amplitude of the relevant confidence intervals. Hence, the effect of nanofiller on tensile strength is statistically significant. Both nanostructured materials show smaller elongations at break, and elastic modulus than pristine $\mathrm{PEO}$, indicating that the addition of nanofiller reduces material elasticity. The copolymer PVDFCTFE shows an opposite behavior. Membrane stress at break decreases with the addition of nanoadditives. Samples loaded with fumed silica show a higher elongation at break and a lower elastic modulus than pristine copolymer, thus acquiring ductility.

Results of mechanical characterization of nanostructured PEO and PVDF-CTFE specimens might be interpreted considering the interaction between the nanofillers and the polymer matrix [21]. It can be hypothesized that interfacial interactions occurring between the oxide nanoparticles and the hydrophilic PEO polymer might cause reinforcement of PEO matrix, thus increasing mat rigidity. On the contrary, 


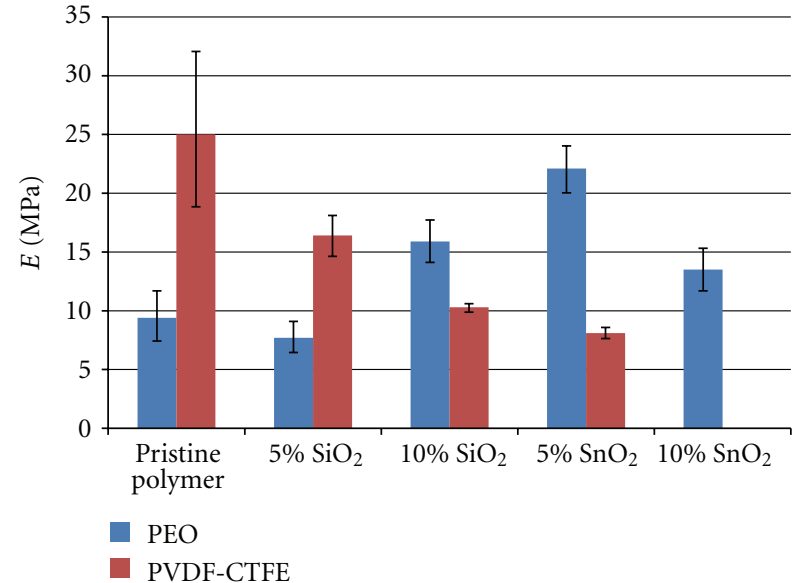

(a)

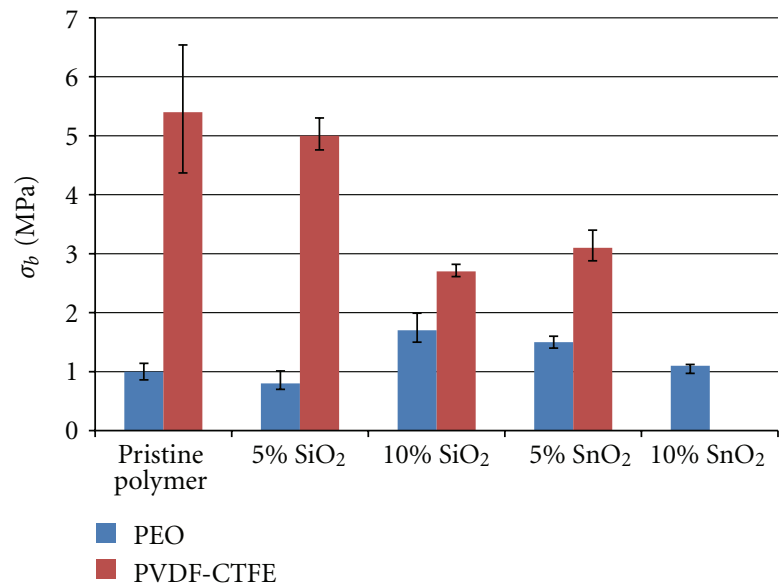

(b)

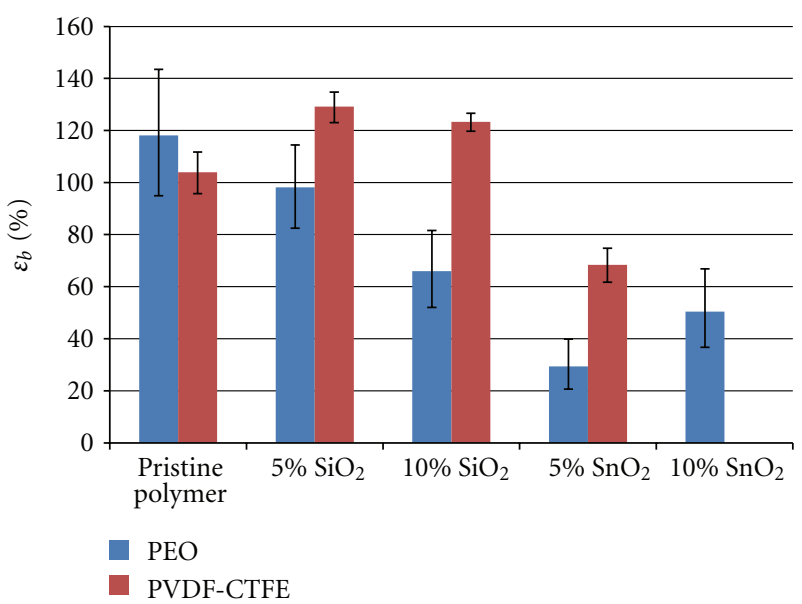

(c)

FIgURE 7: Elastic modulus (a), stress at break (b), and elongation at break (c) of electrospun PEO and PVDF-CTFE membranes.

the poor interaction between oxide nanoparticles and the PVDF-CTFE matrix [22] might explain the decrease in the elastic modulus of the PVDF-CTFE membrane.

\section{Conclusion}

The study carried out on the new materials presented in this paper revealed several positive aspects. First, SEM observations revealed that it was possible to obtain fibres loaded with different types and amounts of metal oxide. The presence of nanoparticles was confirmed by EDS spectroscopy and by thermogravimetric tests, which showed the presence of inorganic compounds as a residue, in amounts proportional to the content added before the electrospinning process. TEM microscope observations gave a feedback of the quality of the inorganic dispersions within the polymeric solution. Nanoparticles aggregation was revealed, demonstrating that an improvement of nanoparticles dispersion within the fibres is needed. Notwithstanding the non optimized particle dispersion, mechanical properties of PEO separators have been improved thanks to the addition of nanoparticles of fumed silica and tin oxide which had the effect of strengthening the fibres. Conversely, a toughening effect was found in the case of PVDF-CTFE membranes loaded with nanoparticles, in particular with fumed silica. Future work will be focused on the improvement of the inorganic phase dispersion in order to obtain a further increase of thermomechanical properties.

\section{Acknowledgment}

This research was carried out with the financial support of the Italian Ministry of Research and University (MIUR).

\section{References}

[1] J. Koryta, Principles of Electrochemistry, John Wiley \& Sons, New York, NY, USA, 2nd edition, 1993.

[2] S. S. Zhang, "A review on the separators of liquid electrolyte Li-ion batteries," Journal of Power Sources, vol. 164, no. 1, pp. 351-364, 2007.

[3] P. Arora and Z. Zhang, "Battery separators," Chemical Reviews, vol. 104, no. 10, pp. 4419-4462, 2004.

[4] Y. J. Kim, C. H. Ahn, and M. O. Choi, "Effect of thermal treatment on the characteristics of electrospun PVDF-silica 
composite nanofibrous membrane," European Polymer Journal, vol. 46, no. 10, pp. 1957-1965, 2010.

[5] P. van de Witte, P. J. Dijkstra, J. W. A. van den Berg, and J. Feijen, "Phase separation processes in polymer solutions in relation to membrane formation," Journal of Membrane Science, vol. 117, no. 1-2, pp. 1-31, 1996.

[6] Y. H. Liao, X. P. Li, C. H. Fu et al., "Polypropylene-supported and nano- $\mathrm{Al}_{2} \mathrm{O}_{3}$ doped poly(ethylene oxide)-poly(vinylidene fluoride-hexafluoropropylene)-based gel electrolyte for lithium ion batteries," Journal of Power Sources, vol. 196, no. 4, pp. 2115-2121, 2011.

[7] K. M. Kim, J. M. Ko, N. G. Park, K. S. Ryu, and S. H. Chang, "Characterization of poly(vinylidenefluoride-co-hexafluoropropylene)-based polymer electrolyte filled with rutile $\mathrm{TiO}_{2}$ nanoparticles," Solid State Ionics, vol. 161, no. 1-2, pp. 121$131,2003$.

[8] G. Derrien, J. Hassoun, S. Sacchetti, and S. Panero, "Nanocomposite PEO-based polymer electrolyte using a highly porous, super acid zirconia filler," Solid State Ionics, vol. 180, no. 23-25, pp. 1267-1271, 2009.

[9] J. K. Lee, Y. J. Lee, W. S. Chae, and Y. M. Sung, "Enhanced ionic conductivity in $\mathrm{PEO}-\mathrm{LiClO}_{4}$ hybrid electrolytes by structural modification," Journal of Electroceramics, vol. 17, no. 2-4, pp. 941-944, 2006.

[10] L. Yan, Y. S. Li, and C. B. Xiang, "Preparation of poly(vinylidene fluoride)(pvdf) ultrafiltration membrane modified by nano-sized alumina $\left(\mathrm{Al}_{2} \mathrm{O}_{3}\right)$ and its antifouling research," Polymer, vol. 46, no. 18, pp. 7701-7706, 2005.

[11] P. Vickraman and V. Senthilkumar, "A study on the role of $\mathrm{BaTiO}_{3}$ in lithum bis(perfluoroethanesulfonyl)imide-based PVDF-HFP nanocomposites," Ionics, vol. 16, no. 8, pp. 763$768,2010$.

[12] M. Walkowiak, M. Osińska, T. Jesionowski, and K. SiwińskaStefańska, "Synthesis and characterization of a new hybrid $\mathrm{TiO}_{2} / \mathrm{SiO}_{2}$ filler for lithium conducting gel electrolytes," Central European Journal of Chemistry, vol. 8, no. 6, pp. 13111317, 2010.

[13] F. Croce, G. B. Appetecchi, L. Persi, and B. Scrosati, "Nanocomposite polymer electrolytes for lithium batteries," Nature, vol. 394, no. 6692, pp. 456-458, 1998.

[14] S. Ramakrishna, K. Fujihara, W. E. Teo, T. C. Lim, and Z. $\mathrm{Ma}$, An Introduction to Electrospinning and Nanofibers, World Scientific, River Edge, NJ, USA, 2005.

[15] F. Croce, M. L. Focarete, J. Hassoun, I. Meschini, and B. Scrosati, "A safe, high-rate and high-energy polymer lithiumion battery based on gelled membranes prepared by electrospinning," Energy and Environmental Science, vol. 4, no. 3, pp. 921-927, 2011.

[16] M. Rao, X. Geng, Y. Liao, S. Hu, and W. Li, "Preparation and performance of gel polymer electrolyte based on electrospun polymer membrane and ionic liquid for lithium ion battery," Journal of Membrane Science, vol. 399-400, pp. 37-42, 2012.

[17] A. I. Gopalan, P. Santhosh, K. M. Manesh et al., "Development of electrospun PVdF-PAN membrane-based polymer electrolytes for lithium batteries," Journal of Membrane Science, vol. 325, no. 2, pp. 683-690, 2008.

[18] Y. Liang, L. Ji, B. Guo et al., "Preparation and electrochemical characterization of ionic-conducting lithium lanthanum titanate oxide/polyacrylonitrile submicron composite fiber-based lithium-ion battery separators," Journal of Power Sources, vol. 196, no. 1, pp. 436-441, 2011.

[19] Y. Ding, P. Zhang, Z. Long, Y. Jiang, F. Xu, and W. Di, "Preparation of PVdF-based electrospun membranes and their application as separators," Science and Technology of Advanced Materials, vol. 9, no. 1, Article ID 015005, 4 pages, 2008.

[20] S. H. Tan, R. Inai, M. Kotaki, and S. Ramakrishna, "Systematic parameter study for ultra-fine fiber fabrication via electrospinning process," Polymer, vol. 46, no. 16, pp. 6128-6134, 2005.

[21] T. Tanaka, "Interface properties and surface erosion resistance," in Dielectric Polymer Nanocomposites, K. Nelson, Ed., pp. 229-258, Springer, New York, NY, USA, 2010.

[22] J. W. Kim, W. J. Cho, and C. S. Ha, "Morphology, crystalline structure, and properties of poly(vinylidene fluoride)/silica hybrid composites," Journal of Polymer Science B, vol. 40, no. 1, pp. 19-30, 2002. 

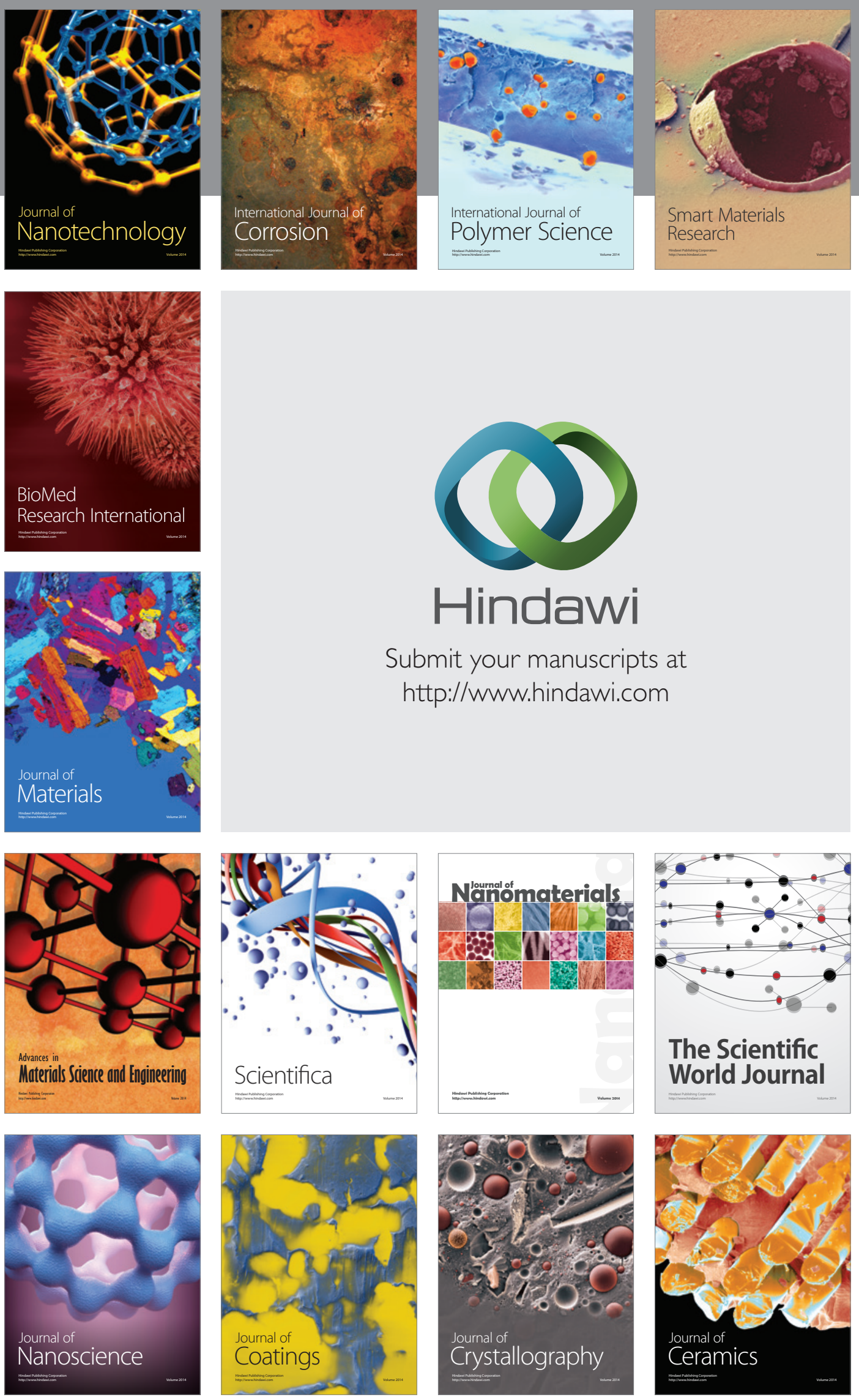

The Scientific World Journal

Submit your manuscripts at

http://www.hindawi.com

\section{World Journal}

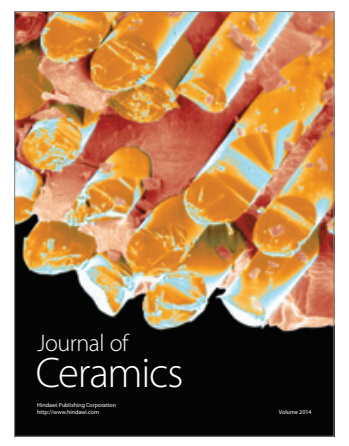

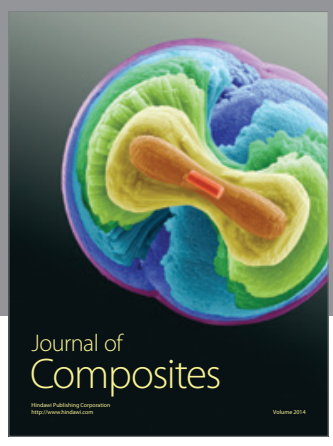
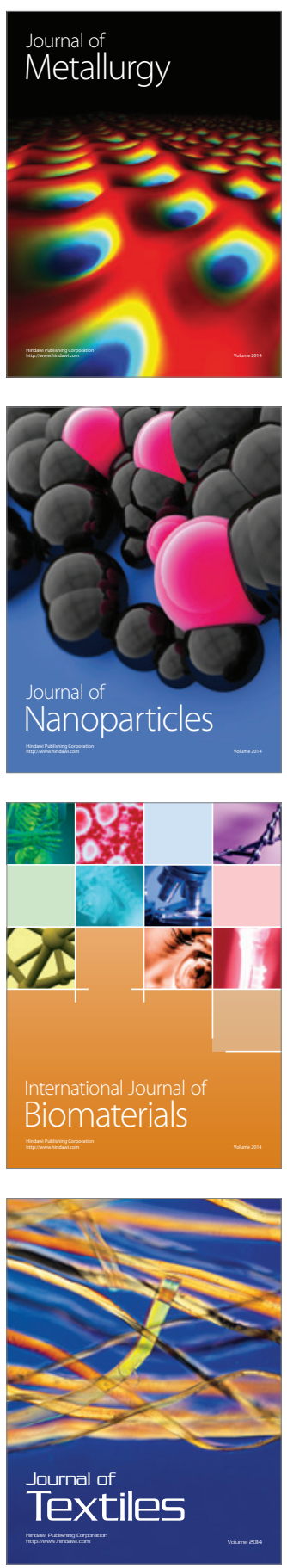